\title{
Re-evaluating the strength of pit-latrine faecal sludge from dynamic cone penetrometer test data
}

\author{
Yasmine Shafiq ${ }^{1}$, Stuart Haigh ${ }^{2}$, Rochelle $\mathrm{Holm}^{3}$ and Alison Parker \\ 'Mott MacDonald, 22 Station Road, Cambridge, United Kingdom \\ ${ }^{2}$ Department of Engineering, University of Cambridge, Trumpington St, Cambridge, United Kingdom \\ ${ }^{3}$ Centre of Excellence in Water and Sanitation, Mzuzu University, P/Bag 201, Mzuzu, Malawi \\ ${ }^{4}$ Cranfield Water Science Institute, Cranfield University, College Road, Cranfield, United Kingdom
}

In $2017,55 \%$ of the global population were without safely managed sanitation services. On-site sanitation solutions, such as pit latrines, provide the majority of sanitation coverage across developing countries. Appropriate technologies are required in order to safely empty these latrines without damage to people or the environment. The design of appropriate emptying technologies can be hampered by a lack of knowledge of the mechanical properties of the waste, such as its strength. This paper will develop a calibration for a dynamic cone penetrometer to give accurate measurements of faecal sludge strength against a standard scale, rendering existing data comparable. It will be shown that the maximum shear strengths of faecal sludge found in practice are substantially greater than those previously reported; some pit latrines contain faecal sludge with strength values of 5-20 kPa at the surface, and exceeding $80 \mathrm{kPa}$ at depth.

\section{INTRODUCTION}

In $2017,55 \%$ of the global population were without safely managed sanitation services and 673 million people practised open defecation (WHO and UNICEF, 2019). On-site solutions provide the majority of sanitation coverage across developing countries (Strande et al., 2014), and over 65\% of sanitation coverage in the urban areas of sub-Saharan Africa (Strauss et al., 2000). The urban population size is projected to increase by 2.6 billion people by 2050 (UN-DESA, 2011), with most of this growth expected to occur in developing countries (Satterthwaite, 2007).

The pit latrine is an on-site sanitation solution whereby excreta is deposited through a drop hole into a below-ground pit, often alongside anal cleansing materials and menstrual cloths, amongst other solid waste. Pit latrines are often used for domestic waste disposal in many areas (Chiposa et al. 2017). In densely populated informal settlements, space limitations necessitate that pits are emptied once they become full; this contrasts with most rural areas, where full pits can be covered with soil and replaced by a new pit in a different location. The majority of mechanical pit emptying technologies used in urban areas use vacuum systems which can only remove the liquid fractions from the surface of the pit (Kwach, 2008), often resulting in an accumulation of unpumpable sludge at the bottom of the pit. This gradually reduces the available pit volume, increasing the frequency with which the pit must be emptied and thereby causing unsustainable increases in the annual cost of pit emptying. Ultimately, users are often forced to resort to unsafe, unhygienic and frequently illegal alternatives, such as pit diversion, flooding out or manual emptying (Jenkins et al., 2015).

Improving the effectiveness and affordability of mechanical pit emptying would reduce the prevalence of these dangerous practices and therefore decrease the extent to which people come into direct contact with faecal waste, due to both unsafe pit emptying practices and uncontrolled disposal of the removed material. However, a lack of data on the physical properties of faecal sludge currently restricts the development of improved pit emptying technologies.

The first study into the physical properties of faecal sludge, by Bösch and Schertenleib (1985), characterised the contents of 85 pits in Gaborone, Botswana, in terms of viscosity and density. Shear strength has since been used as a more appropriate measure of sludge state than viscosity, as consolidated faecal sludge does not readily flow, rather it behaves more like a solid than a fluid (Radford and Sugden, 2014). The undrained shear strength of faecal sludge dictates whether the pit latrine material will begin to flow at a given suction (Radford et al., 2015).

Radford and Fenner (2013) converted the viscosities recorded by Bösch and Schertenleib (1985) into approximate shear strength values. The maximum undrained shear strength calculated was $400 \mathrm{~Pa}$. It should be noted, however, that the viscometer testing in Bösch and Schertenleib (1985) was carried out on the strongest sludge which could be removed by the available vacuum tankers, rather than on the strongest sludge present in the pit, and after it was disturbed by removal and transport.

Penetrometers can produce continuous profiles of faecal sludge strength with depth into a latrine pit, with some designs being sufficiently inexpensive for wide-scale testing across developing countries. A variety of penetrometer designs have been used to measure shear strength profiles within latrine pits.

Radford and Sugden (2014) used a mechanised portable penetrometer to measure the resistance to penetration of the faecal sludge in 30 pits in Kampala, Uganda. This penetrometer was not calibrated

\section{CORRESPONDENCE}

Yasmine Shafiq

\section{EMAIL}

yasmineshafiq@hotmail.com

\section{DATES}

Received: 18 December 2019

Accepted: 10 September 2020

\section{KEYWORDS}

faecal sludge strength measurement dynamic cone penetrometer pit latrine

\section{COPYRIGHT}

() The Author(s) Published under a Creative Commons Attribution 4.0 International Licence (CC BY 4.0) 
to a standard measure of shear strength, but rather to the miniball penetrometer developed by Kuo (2011) for testing the shear strengths of weak marine sediments. Radford and Sugden (2014 p. 185) collected data from pit latrines at varied heights above the water table with varying construction types: 'from deep unlined pits sited well above the water table, to shallow lined vaults down in the valley'. The portable penetrometer used by Radford and Sugden (2014) was designed to measure strengths up to $2 \mathrm{kPa}, 5$ times stronger than the previously reported maximum of $400 \mathrm{~Pa}$. Despite this, faecal sludge with strengths exceeding the 'portable' penetrometer's maximum reading was found in 7 of the 30 pits. While $87 \%$ of the tested pits contained some 'weak sludge of comparable strength to that previously reported', $60 \%$ of them were also found to contain sludge which was stronger than $400 \mathrm{~Pa}$.

Radford et al. (2015) collected existing data on the shear strength and bulk density of faecal sludge. The highest undrained shear strength directly measured was $2 \mathrm{kPa}$, but rheological data which was extrapolated from weaker samples in Woolley et al. (2014a, b) suggested that the maximum shear strength of faecal sludge could be $10 \mathrm{kPa}$, for sludge with total solids contents of up to $40 \%$.

Alongside limited data collection on the absolute shear strength of pit latrine faecal sludge, dynamic cone penetrometers (Sowers and Hedges, 1966), originally developed for the testing of road materials, have been used to qualitatively assess sludge strength The test involves a falling weight driving a cone into the sludge, with data collected in the form of penetration distance per impact. Chiposa et al. (2017), Chirwa et al. (2017) and Seal et al. (2018) have used these penetrometers to qualitatively assess faecal sludge strength. However, the penetrometer specifications varied in total mass, hammer mass and hammer drop height across these papers, rendering the absolute values of penetration distance per impact incomparable.

This paper calibrates existing data from dynamic cone penetrometers against a conventional measure of shear strength and hence reinterprets this data to provide revised guidance on the strength of in-situ pit latrine faecal sludge.

\section{METHODS}

\section{The mechanics of cone penetration}

Two modes of penetration are of interest when interpreting data from dynamic cone penetrometers. For very weak sludges, the penetrometer may sink under its own weight without any blows being imposed, whereas, for stronger sludges, the penetrometer will move a finite distance with each impact.

The resistance to sinking of a penetrometer at shallow depths can be studied by comparison with the failure of a circular shallow foundation. Skempton (1951) proposed that the relationship between the downwards stress to cause a circular foundation to fail, $q_{\mathrm{f}}$, and the shear strength, $c_{\mathrm{u}}$, of the underlying soil was given by:

$$
q_{\mathrm{f}}=6.2 c_{\mathrm{u}}
$$

By considering the downwards stress to be caused by the mass of the penetrometer, $m$, acting on a circular foundation with area equal to the projected cone area, it can be shown that:

$$
c_{\mathrm{u}}=\left(\frac{m_{\text {static }} g}{6.2 \pi\left(\frac{d}{2}\right)^{2}}\right)=0.205 \mathrm{~m} \frac{g}{d^{2}}
$$

When impacts are used to drive the penetrometer, the mechanics of the system can be analysed by considering the conservation of energy, with the potential energy of the falling weight being dissipated plastically within the sludge, as shown in Eq. 3.

$$
6.2 \frac{\pi d^{2}}{4} c_{\mathrm{u}} \Delta=\left(m_{\text {hammer }} h+m d_{p}\right) g
$$

where $\Delta$ is the penetration distance per impact, $m_{\text {hammer }}$ is the mass of the hammer, $h$ is the distance over which the hammer is dropped and $m$ is the total mass of the penetrometer, including the hammer.

Equation 4 can be derived by rearranging Equation 3 for $c_{\mathrm{u}}$.

$$
c_{\mathrm{u}}=0.2 \frac{g}{d^{2}}\left(\frac{m_{\text {hammer }} h}{\Delta}+m\right)
$$

It should be noted that energy losses have been ignored within this equation. Hence, a calibration must be carried out on the penetrometer to investigate the energy losses during impacts, which will result in amendments to Eq. 4 .

\section{Penetrometer calibrations}

In order to calibrate the dynamic cone penetrometer as a measurement of sludge strength, a simulated sludge for which strength could be measured by standard methods was required as a testing material. The composition of the faecal sludge simulant selected for this project was $60 \%$ Speswhite kaolin clay and $40 \%$ topsoil, by dry mass. This was selected on the basis of Radford (2014), as representative of the 'stickiness' of faecal sludge, and Underdown (2013), who suggested that the undrained shear strength of the faecal sludge simulant would be most sensitive to water content at this sludge composition. The topsoil was sieved through a $6.7 \mathrm{~mm}$ mesh, to increase the homogeneity of the resulting mixture. The strength of the sludge simulant was varied by altering the water content at which it was mixed. Water content has been defined inconsistently in the previous work on faecal sludge strength, with two definitions being used. In this work, both formulations are shown for comparison.

$$
\mathrm{WC}_{\mathrm{w}}=\frac{\text { mass of water }}{\text { total mass }} \quad \mathrm{WC}_{\mathrm{d}}=\frac{\text { mass of water }}{\text { mass of solids }}
$$

Sixteen batches of faecal sludge simulant were prepared, with shear strengths ranging from 4-20 kPa. Water contents were measured after mixing according to the method of BSI (2014) by drying a small (approximately $50 \mathrm{~g}$ ) sample of sludge of known weight in an oven at $110^{\circ} \mathrm{C}$ for $24 \mathrm{~h}$ and assuming that the weight change due to oven drying corresponded to the water present in the sample and the remaining sample weight corresponded to the solids. Samples were weighed using a precision balance accurate to $0.01 \mathrm{~g}$. This measurement assumes that no organic solids within the sludge decompose on oven-drying. If any solids decompose on heating this will give a systematic error in the measurement of sludge water content but will have no effect on the calibration of the penetrometer detailed in this paper as this purely relies on the relationship between the vane-shear strength and penetrometer resistance of identical samples.

For each batch of faecal sludge simulant, the undrained shear strength was measured using a shear vane. In a shear-vane test, a vane of known geometry (Fig. 1a) is rotated in the sludge with a calibrated spring within the handle (Fig 1b), measuring the applied torque. The maximum recorded torque can be converted to a shear strength by integrating stresses over the cylindrical failure surface.

The strength variation of the sludge simulant is shown against water content in Fig. 2. The sludge strength varies semi-logarithmically with water content, as is consistent with work on soil strength by Vardanega and Haigh (2014), with strengths given by:

$$
c_{\mathrm{u}}(\mathrm{kPa})=10^{\left(6.2-17 \mathrm{WC}_{\mathrm{w}}\right)}=10^{\left(4.6-8.0 \mathrm{WC}_{\mathrm{d}}\right)}
$$



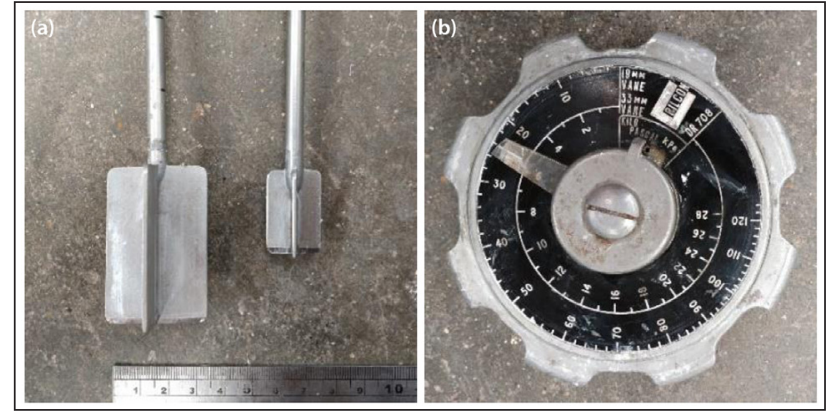

Figure 1. Shear vane test apparatus

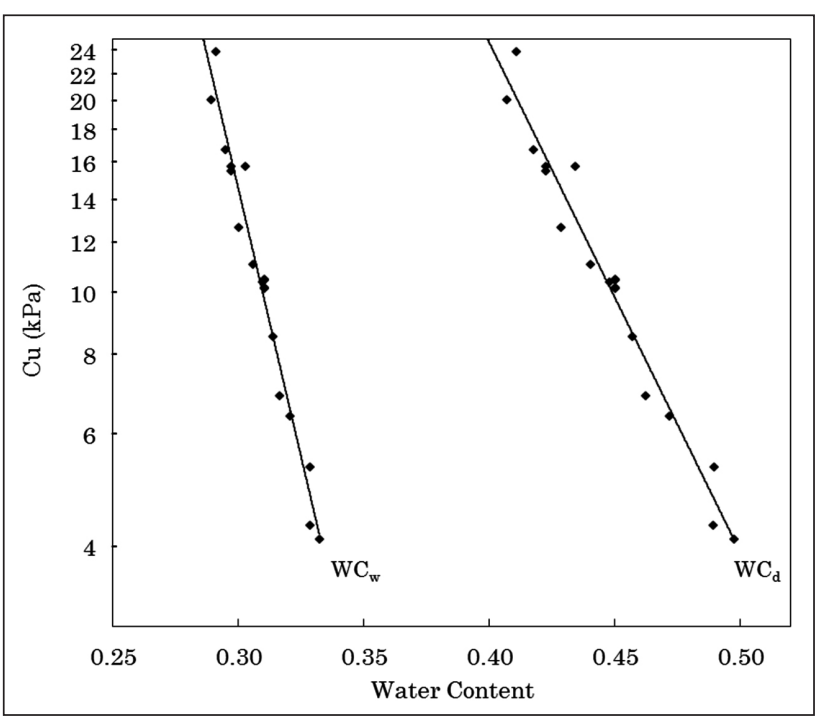

Figure 2. Variation of faecal sludge simulant strength with water content

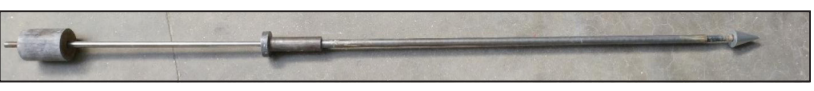

Figure 3. Dynamic cone penetrometer

Table 1. Mass of penetrometer components

\begin{tabular}{lc}
\hline Component & Mass $(\mathbf{k g})$ \\
\hline Anvil & 0.61 \\
Top rod & 0.53 \\
Cone and drive rod & 1.28 \\
Hammers & 2,1 or 0.51 \\
\hline
\end{tabular}

A modular dynamic cone penetrometer was developed, as shown in Fig. 3. This allowed the self-weight, cone geometry and falling mass properties to be easily varied.

The cone used in the tests described here was $55 \mathrm{~mm}$ long and $35 \mathrm{~mm}$ in diameter, as used in the penetrometer developed by North Carolina State University and used by Seal et al. (2018), Chirwa et al. (2017) and Chiposa et al. (2017). The drive rod had a diameter of $16 \mathrm{~mm}$, leading to the masses of penetrometer components shown in Table 1.

\section{RESULTS AND DISCUSSION}

\section{Static penetrometer calibration}

In order to test the theoretical model proposed in Eq. 2, the relationship between the mass required to cause static failure, $m$, and measured sludge strength, $c_{\mathrm{u}}$, was investigated experimentally. $m$ was measured for 8 batches of faecal sludge, for each of which the shear strength had been measured using the vane, by supporting the shaft of the penetrometer in a vertical orientation with the tip of the cone resting on the surface of the sludge and incrementally increasing the mass until the penetrometer began to sink at a rate of approximately $2 \mathrm{~mm} \cdot \mathrm{s}^{-1}$.

Figure 4 shows a linear relationship between $m$ and $c_{\mathrm{u}}$. A linear trendline through the origin, consistent with the theoretical relationship, is also shown with a good fit to the data $\left(R^{2}=0.96\right)$. The equation of this line is $c_{\mathrm{u}}=1.663 \mathrm{~m}$ (where $c_{\mathrm{u}}$ is in $\mathrm{kPa}$ and $m$ is in $\mathrm{kg}$ ). This is consistent with Eq. 2 for a $35 \mathrm{~mm}$ diameter cone, which would give $c_{\mathrm{u}}=1.642 \mathrm{~m}$. Equation 2 is thus seen to provide a suitable model for analysing the strength of sludge sediments, if the weight required to cause steady penetration at the surface is known.

\section{Dynamic penetrometer calibration}

The relationship between penetration per blow, $\Delta$, and sludge shear strength, $c_{\mathrm{u}}$, was investigated experimentally, in order to test the theoretical model proposed by Eq. 4 and to assign appropriate parameters to account for energy losses. The dynamic penetration, $\Delta$, was measured across 16 batches of faecal sludge simulant, by supporting the penetrometer in a vertical position with its tip resting on the surface of a bucket of sludge simulant and then dropping the hammer from a height $h$ onto the anvil. The penetration distance was then measured with a tape measure. $\Delta$ values were recorded for penetrometer depths between $57 \mathrm{~mm}$ beneath the surface of the sludge (above which, the cone was not fully submerged) and $10 \mathrm{~mm}$ from the base of the soil container (below which, boundary conditions would cause errors). 132 data points were recorded across a range of values of $m_{\text {hammer }} h, c_{\mathrm{u}}$ and $m$.

Figure 5 shows the relationship between the shear strength predicted using Eq. $4, c_{\text {u-penetrometer }}$ and that measured using the shear vane, $c_{\mathrm{u} \text {-vane. }}$. It can be seen that while a strong linear correlation exists between the two strength measures, this varies substantially from equality. A linear fit to the data results in a trendline given by:

$$
c_{\mathrm{u}-\text { vane }}=0.17 c_{\mathrm{u}-\text { penetrometer }}+4.5 \mathrm{kPa}, R^{2}=0.754
$$

Equation 4 can thus be seen to substantially overestimate the actual strength of the sludge simulant, owing to energy losses during the hammer impact process and possible strain-rate effects.

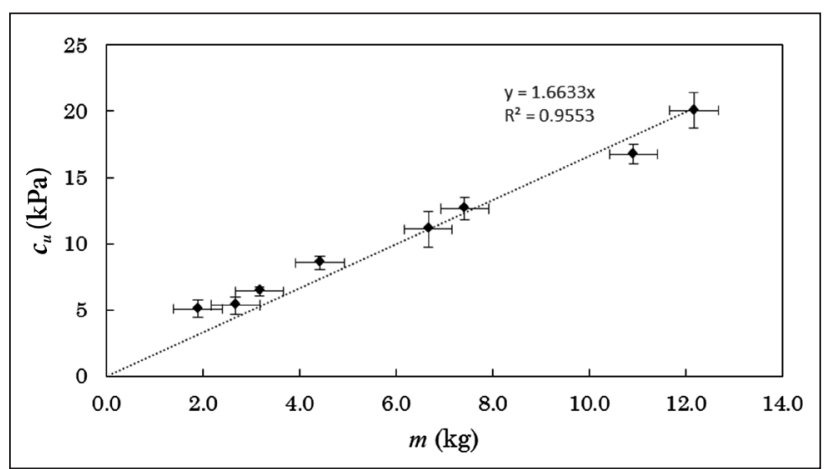

Figure 4. Static penetration test data

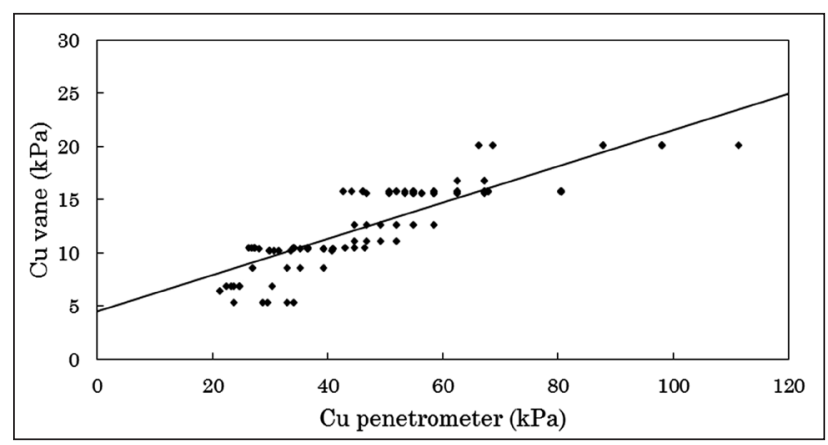

Figure 5. Relationship between measured strengths and those predicted by Equation 4 
Equation 4 was therefore modified with the correction factor $\beta$, to form Equation 8.

$$
c_{\mathrm{u}}=0.2 \frac{g}{d^{2}}\left(\frac{\beta m_{\text {hammer }} h}{\Delta}+m\right)
$$

Physically, $\beta$ accounts for inefficiencies in the conversion from the gravitational potential energy of the hammer to the energy dissipated by plastic deformation of the faecal sludge simulant. Assuming $\beta$ to be constant, a best fit to the data is found with a value $\beta=0.186$. However, Eq. 8 with $\beta=0.186$ consistently overestimates shear strength by $1.1 \mathrm{kPa}$.

Adding a second factor $\alpha$, to form Eq. 9, allows a good fit to be achieved between measured and predicted values of shear strength with no systematic bias. This is shown in Fig. 6. A leastsquares analysis was carried out in the curve fitting toolbox of MATLAB using the measured penetrometer data and vane-shear strengths and assuming a relationship of the form given by Eq. 9 . The best fit values of $\alpha$ and $\beta$ were found to be $\alpha=0.827, \beta=0.222$, giving an $R^{2}$ value of 0.797 .

$$
c_{\mathrm{u}}=0.2 \alpha \frac{g}{d^{2}}\left(\frac{\beta m_{\text {hammer }} h}{\Delta}+m\right)
$$

Physically, $\alpha$ accounts for frictional effects on the penetrometer cone, which may be greater in impact testing than in the bearing strength testing, due to high dynamic normal stresses.

While Fig. 6 still shows a limited degree of residual scatter, no correlation was found with any experimental parameter. The scatter thus seems to be related to heterogeneity within the sludge simulant which was assumed from the vane shear data to be of constant strength throughout each sample.

It should be noted that this model has only been calibrated for faecal sludge simulants with undrained shear strengths up to approximately $20 \mathrm{kPa}$, attempts to mix stronger faecal sludge simulant having been unsuccessful. It is recommended that this experiment should be replicated with in-situ pit latrine faecal sludge in order to check the suitability of the derived $\alpha$ and $\beta$ values for real-world conditions of faecal sludge.

\section{Application to field data}

The dynamic cone penetrometers used by Chiposa et al. (2017), Chirwa et al. (2017) and Seal et al. (2018) had a $35 \mathrm{~mm}$ diameter cone, consistent with that used for the calibration presented above. The masses of the penetrometers were dependent on the number of rods attached. Minimum and maximum values (including the hammer and rods) are shown in Table 2.
These minimum penetrometer mass values were substituted into Eq. 4 to find the shear strength value at which the penetrometer would sink through sludge under its own weight with one rod attached, $c_{\mathrm{u}-\text { sink }}$. The results are shown in Table 2 and represent the minimum sludge strengths that can be measured by these devices. It should be noted that these values, at around $6 \mathrm{kPa}$, are substantially greater than the sludge strengths reported in previous work, yet only in 21 of the 439 pits tested did the penetrometer sink to the base of the pit with no blows. This indicates that in any pit latrine for which dynamic cone penetrometer testing has been carried out and a blow-count reported, the sludge strength must exceed $6 \mathrm{kPa}$ and hence be greater than the upper limit of $2 \mathrm{kPa}$ previously proposed by Radford et al. (2015).

The model proposed in Eq. 8 has been applied to raw data from Chiposa et al. (2017), using $\alpha=0.827$ and $\beta=0.222$, to calculate the strengths of faecal sludge measured in latrines in Mzuzu, Malawi. Figure 7 shows the strength profile for all 30 pits tested. The inferred strength of the faecal sludge tends to be around $20 \mathrm{kPa}$ at shallow depths before rapidly increasing to over $80 \mathrm{kPa}$ at some variable depth. It is likely that the weaker material represents recently deposited waste, whereas the stronger deeper layers are material which has been strengthened by ageing.

Chiposa et al. (2017) attempted emptying for the 30 pits, using the modified Gulper pump which had been developed in Chipeta et al. (2017). Pits were classified based on whether they could be emptied using this pump, with red profiles shown in Fig. 7 being emptiable. As noted in Chiposa et al. (2017), the penetrometer profile of each pit was not necessarily a good indicator of whether it could be emptied with the modified Gulper pump. For example, some pits with relatively weak sludge were not possible to empty due to high trash volumes. Additionally, 'emptying' of the pit does not necessarily imply removal of all the weak material; this may merely be removal of surficial deposits through which the penetrometer sank without resistance.

While the calculated strength values exceed those for which Eq. 9 was calibrated, it is evident that the faecal sludge in the 30 pits studied by Chiposa et al. (2017) is significantly stronger than the maximum shear strength value previously measured.

Our model was further applied to data from 114 latrines in Kibera, Nairobi, Kenya, reported by Seal et al. (2018) and 300 latrines in Mzuzu, Malawi, reported by Chirwa et al. (2017). With such a large number of latrines, it is more informative to look at statistical distributions of strength with depth than individual pit latrine profiles.

Table 2. Field penetrometer properties

\begin{tabular}{lccc}
\hline Penetrometer specifications & $\begin{array}{c}\text { Minimum penetrometer } \\
\text { mass: one rod attached (kg) }\end{array}$ & $\begin{array}{c}\text { Maximum penetrometer } \\
\text { mass }(\mathbf{k g})\end{array}$ & $\begin{array}{c}\text { Minimum measurable } \\
\text { sludge strength } \mathbf{c}_{\mathrm{u}-\mathrm{sink}}(\mathbf{k P a})\end{array}$ \\
\hline Seal et al. (2018) & 3.8 & 5.0 & 6.2 \\
Chiposa et al. (2017) and Chirwa et al. (2017) & 3.4 & 5.4 & 5.6 \\
\hline
\end{tabular}

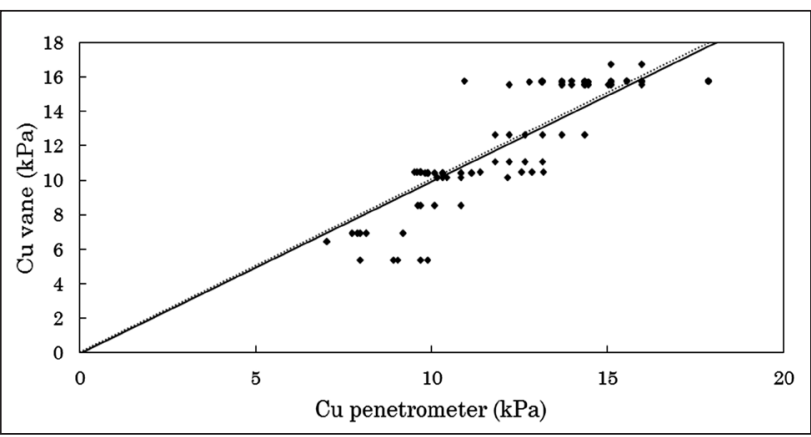

Figure 6. Relationship between measured strengths and those predicted by Equation 9, with $\alpha=0.827$ and $\beta=0.222$

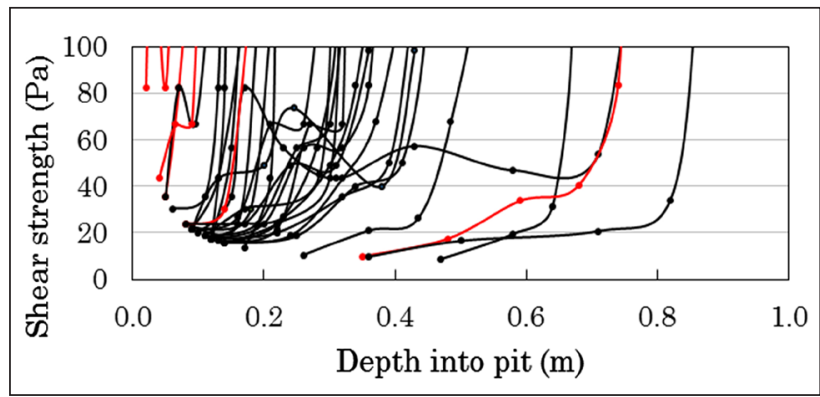

Figure 7. Calculated strength profiles for pit latrines in Mzuzu, Malawi (data from Chiposa et al. 2017). Red lines indicate pit latrines able to be emptied. 

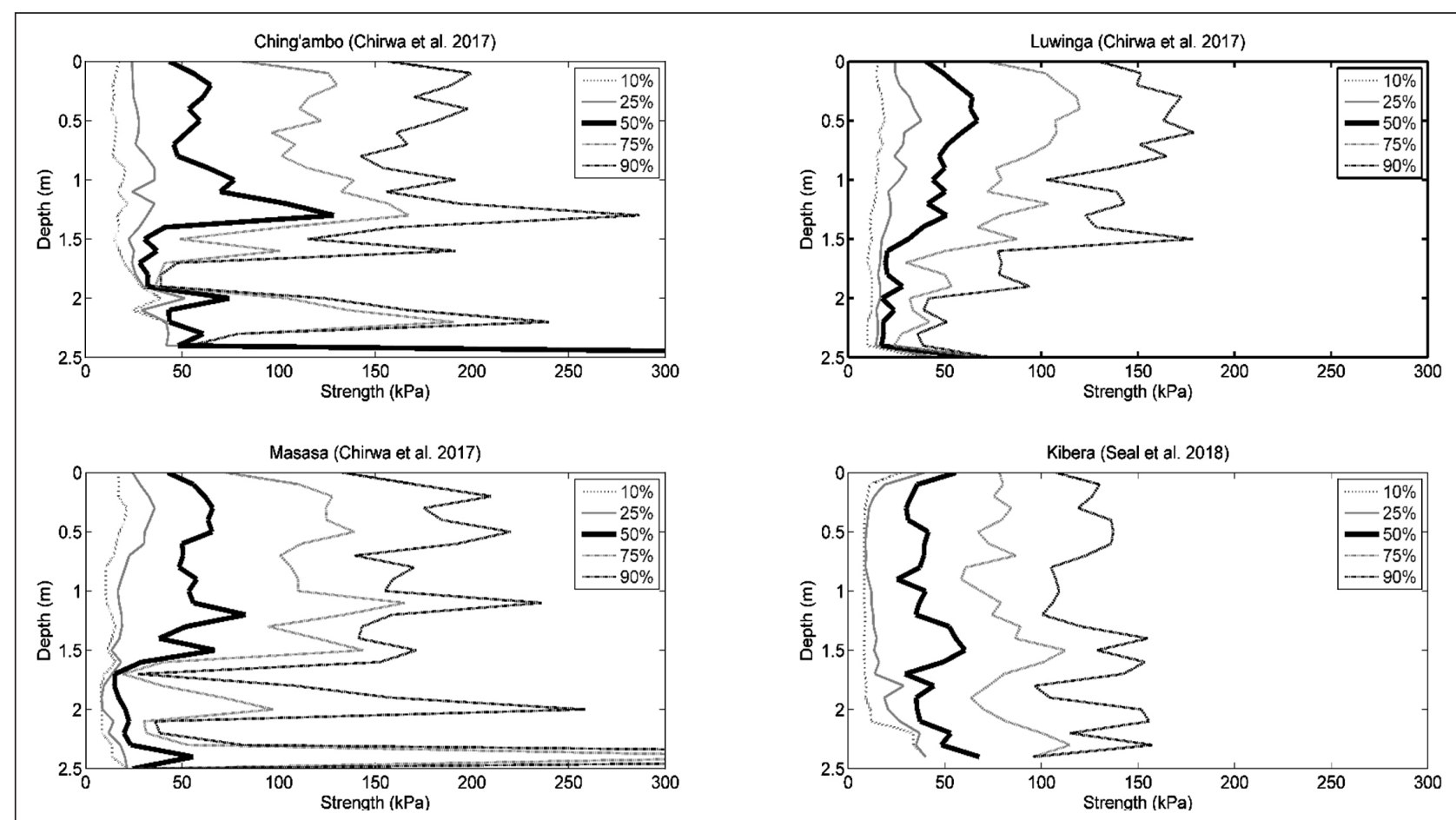

Figure 8. Calculated sludge strength ranges from pit latrines in Mzuzu (data from Chirwa et al., 2017) and Kibera, Nairobi (data from Seal et al., 2018)

Figure 8 shows the percentiles of measured strengths with depth for the 414 latrines. The median measured sludge strength is consistently around $50 \mathrm{kPa}$, remaining approximately constant with depth, with the $25^{\text {th }}$ to $75^{\text {th }}$ percentiles spanning the range $20-80 \mathrm{kPa}$. It should be noted that penetration ceased when the penetrometer could no longer be advanced due to the strength of the sludge. This may result in a bias in the reported strength at depth, as penetrometers in stronger sludges will never have reached greater depths and so will not be included in the averages. This may result in strengths at depth being an underestimate of the true values. The data plotted in Fig. 8 show the strength of the solid sludge layer through which the penetrometer did not sink under its own weight. Above this layer was a layer of weaker sludge for which the penetrometer was not suitable to measure strength. This surface layer had a small thickness in the pits tested in Mzuzu, but in the pits tested in Kibera it had a thickness of $0-2.8 \mathrm{~m}$ with a median value of $0.55 \mathrm{~m}$.

Our results indicate that faecal sludge has a wide strength range, possibly dependent on age, usage practices, pit construction details and the extent to which latrine pits are used for general waste disposal. The faecal strengths observed throughout Chiposa et al. (2017), Chirwa et al. (2017) and Seal et al. (2018) are, however, substantially higher than those which have been previously reported.

\section{Application to practice}

Faecal sludge strength is one of several parameters defining the pump technology required to empty a pit latrine, but inexpensive methods to quantify that waste strength, in order to scale pumps, are currently lacking. Our calibration of the dynamic penetrometer has allowed a tool suitable for use in developing countries to produce accurate measurements of sludge strength profiles with depth.

In order to ease the use of this specific technology in the field, design charts have been produced, using Eq. 4, for static penetration (Fig. 9) and Eq. 8 for dynamic penetration with a drop height of $500 \mathrm{~mm}$ (Fig. 10). These design charts enable dynamic penetrometer users to assess faecal sludge strength. In practice, lines could be superimposed on these charts to represent appropriate technologies for pit emptying.
While the penetrometer equipment reported by Seal et al. (2018), Chiposa et al. (2017) and Chirwa et al. (2017) differ in their details, our results indicate that minor changes in component masses make limited differences to the strengths calculated. Corrections are possible based on the number of rods used, as shown in Fig. 11, but this correction may well be unnecessary to give an adequate strength estimate for pump selection.

In the field, initially, a static strength test can be performed with an unloaded penetrometer to assess the depth at which the sludge strength is equal to the minimum measurement capability of the device (Table 2). A dynamic test should then be carried out, dropping an appropriate weight from a height of $500 \mathrm{~mm}$ in order to characterise the strength of the underlying stronger material. The charts presented herein would then enable pit emptiers to determine the shear strength of faecal sludge with this as a leading test, and thereby select an appropriate methodology for emptying the pit.

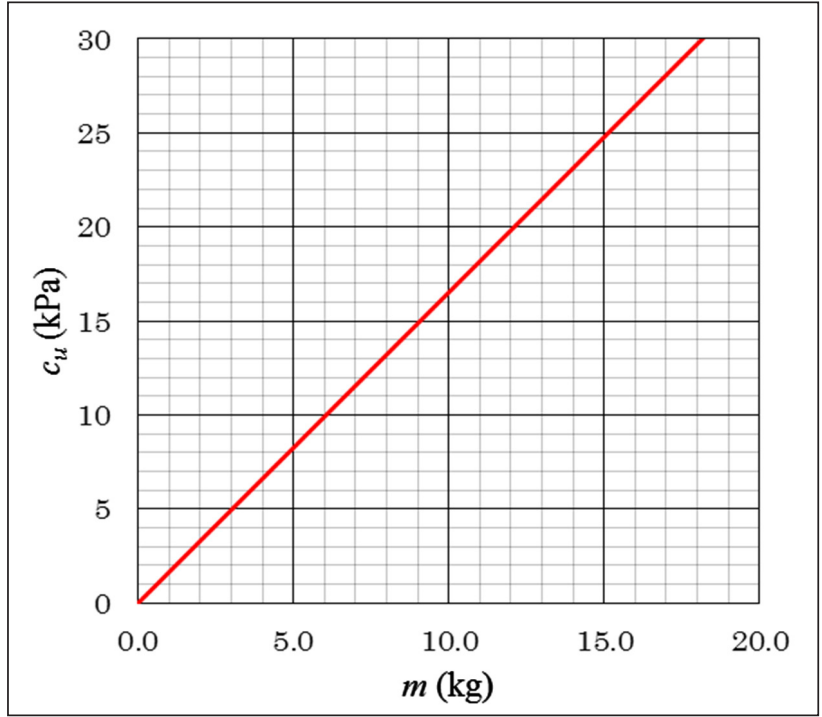

Figure 9. Design chart for strength of sludge at which penetrometer sinks under self-weight 


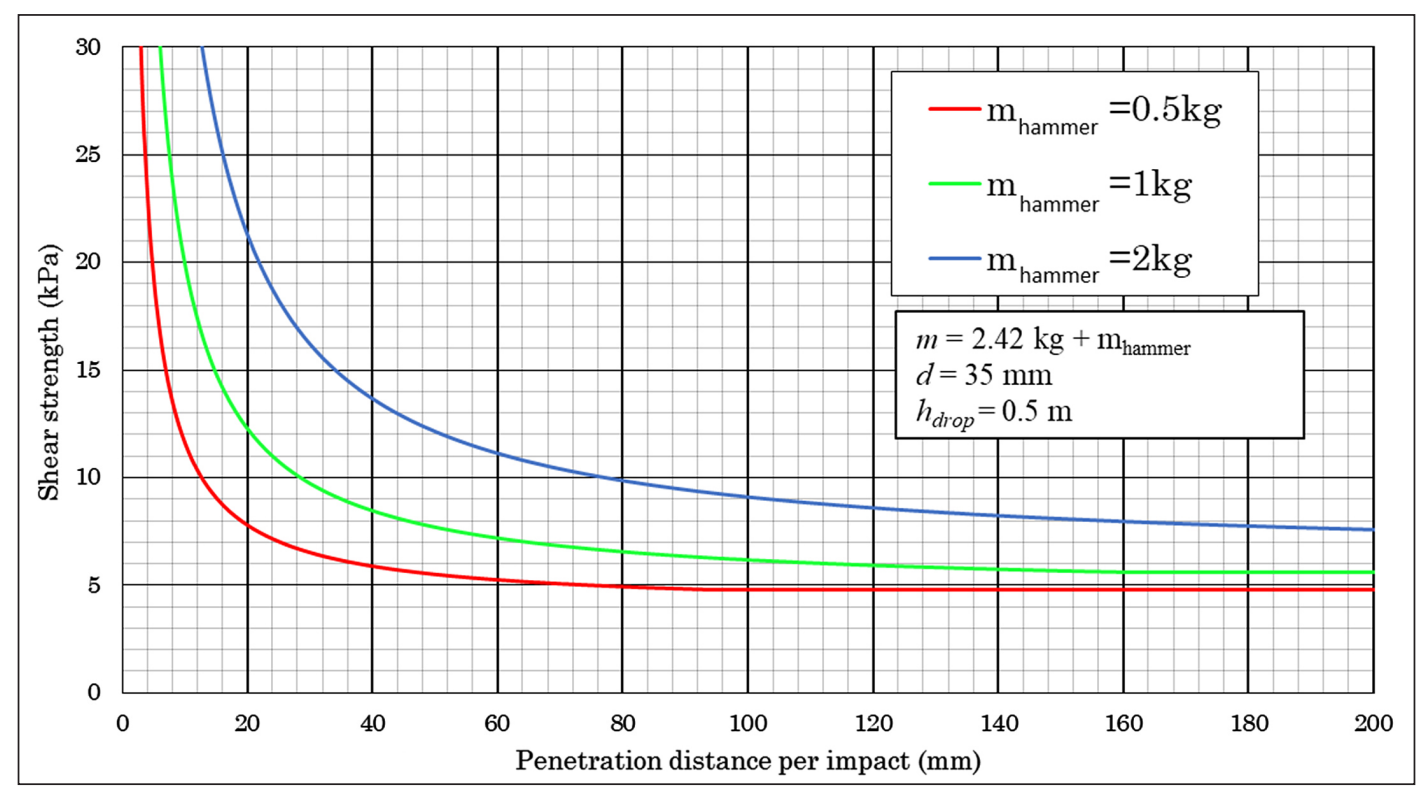

Figure 10. Design chart for estimating $c_{u}$ from a cone penetrometer test

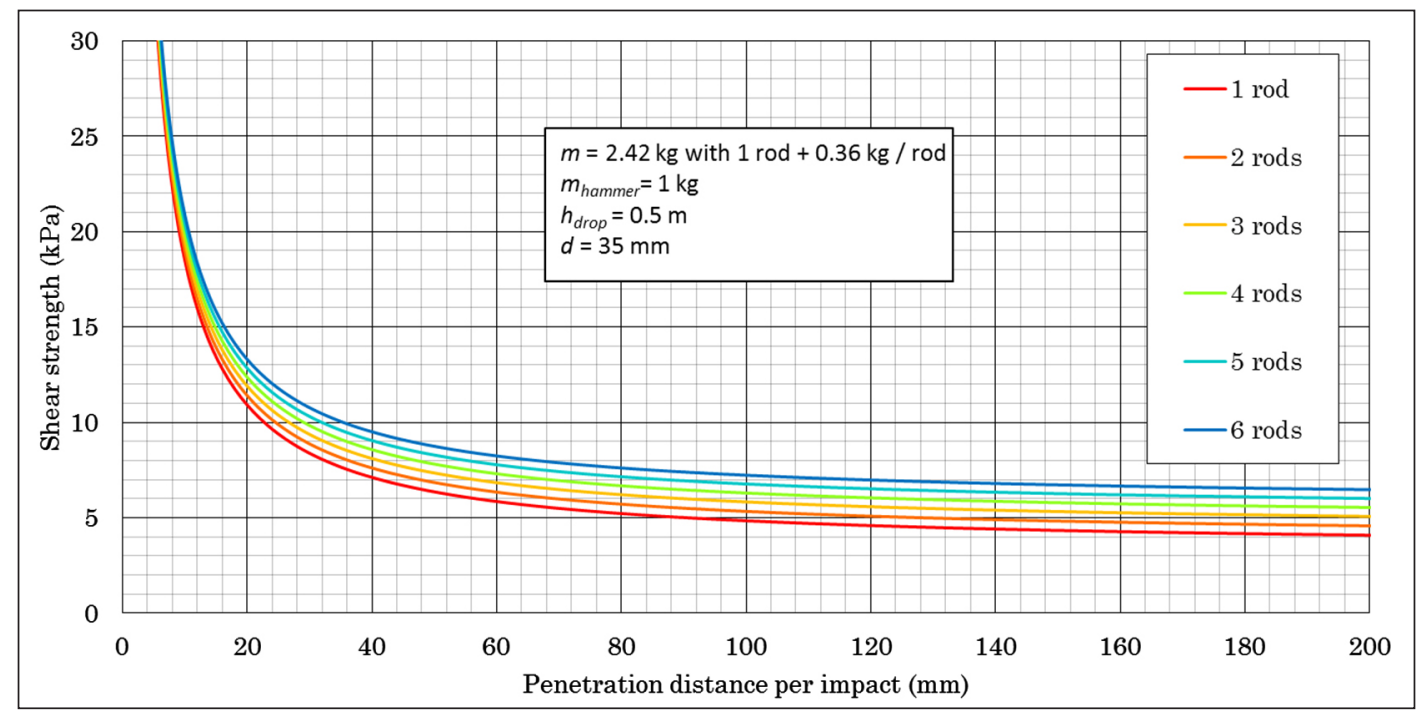

Figure 11. Effect of changing number of rods on inferred strength

\section{CONCLUSIONS}

An experimental calibration has been produced for two simple, inexpensive methods of testing the shear strength of faecal sludge simulant: a static strength test and an impact test, both using a dynamic cone penetrometer. Both tests have been calibrated for the standard cone tip used in previous research. Design charts have been produced, linking the undrained shear strength of the faecal sludge simulant to the minimum self-mass at which the penetrometer begins to sink into the soil without the application of any hammer blows or the measured penetration distance per impact, respectively.

Once the model has been calibrated to in-situ pit latrine faecal sludge, the design charts produced here will give a suitable method of choosing appropriate pit emptying technologies in low-income countries.

While the sludge strengths reported in existing literature are very low, due to the limitations of the equipment used, the use of heavy dynamic cone penetrometers to assess their strength shows that, in these regions at least, strengths can be very high. Data reanalysed from latrine pits in Mzuzu, Malawi and Kibera, Nairobi suggest that while some pits may contain very soft material, strengths of up to $20 \mathrm{kPa}$ near to the surface and greater than $80 \mathrm{kPa}$ at depth are by no means unusual. This has implications for the emptying of pit latrines, as the in-situ sludge may be too strong to be removed manually without mixing in additional water. Mechanised pit emptying techniques are developed to handle sludges of a given strength range; our work implies that substantially higher sludge strengths than previously proposed should be considered.

\section{Notation}

$c_{\mathrm{u}} \quad$ undrained shear strength of the sludge

d diameter of penetrometer cone

$\Delta \quad$ penetration distance per blow

$g \quad$ acceleration due to gravity

$h \quad$ distance by which hammer drops

$m_{\text {hammer }} \quad$ mass of the hammer

$m \quad$ mass of the penetrometer, including the hammer

$m_{\text {static }} \quad$ mass at which the penetrometer sinks into the soil

$\mathrm{WC}_{\mathrm{d}} \quad$ water content, calculated based on dry mass

$\mathrm{WC}_{\mathrm{w}} \quad$ water content, calculated based on wet mass 


\section{REFERENCES}

BÖSCH A and SCHERTENLEIB R (1985) Emptying on-site excreta disposal systems. IRCWD Report 03/85. IRCWD, Zurich.

BSI (British Standards Institute) (2014) British Standard BS EN ISO 17892-1: 2014 - Water Content. British Standards Institute, London.

CHIPETA WC, HOLM RH, KAMANULA JF, MTONGA WE and DE LOS REYES III FL (2017) Designing local solutions for emptying pit latrines in low-income urban settlement (Malawi). Phys. Chem. Earth. 100 336-342. https://doi.org/10.1016/j.pce.2017.02.012

CHIPOSA R, HOLM R, MUNTHALI C, CHIDYA R and DE LOS REYES F (2017) Characterization of pit latrines to support the design and selection of emptying tools in peri-urban Mzuzu, Malawi. J. Water Sanit. Hyg. Dev. 7 (1) 151-155. https://doi.org/10.2166/wash dev.2017.096

CHIRWA C, HALL R, KROMETIS L, VANCE E, EDWARDS A, GUAN $\mathrm{T}$ and HOLM R (2017) Pit latrine fecal sludge resistance using a dynamic cone penetrometer in low income areas in Mzuzu City, Malawi. Int. J. Environ. Res. Public Health. 14 (2) 87. https://doi.org/ 10.3390/ijerph14020087

DODANE PH, MBÉGUÉRÉ M, OUSMANE S and STRANDE L (2012) Capital and operating costs of full-scale faecal sludge management and wastewater treatment systems in Dakar, Senegal. Environ. Sci. Technol. 46 (7) 3705-3711. https://doi.org/10.1021/es2045234

JENKINS M, CUMMING O and CAIRNCROSS S (2015) Pit latrine emptying behavior and demand for sanitation services in Dar Es Salaam, Tanzania. Int. J. Environ. Res. Public Health. 12 (3) 2588 2611. https://doi.org/10.3390/ijerph120302588

KUO M (2011) Deep ocean clay crusts: behaviour and biological origin. $\mathrm{PhD}$ thesis, University of Cambridge.

KWACH H (2008) The UN-HABITAT Vacutug Development Project Update 2008. UN-HABITAT, Nairobi, Kenya.

RADFORD J and FENNER R (2013) Characterisation and fluidisation of synthetic pit latrine sludge. J. Water Sanit. Hyg. Dev. 3 (3) $375-$ 382. https://doi.org/10.2166/washdev.2013.023

RADFORD J and SUGDEN S (2014) Measurement of faecal sludge insitu shear strength and density. Water SA. 40 (1) 183-188. https:// doi.org/10.4314/wsa.v40i1.22

RADFORD J, UNDERDOWN C, VELKUSHANOVA K, BYRNE A, SMITH D, FENNER R, PIETROVITO J and WHITESELL A (2015) Faecal sludge simulants to aid the development of desludging technologies. J. Water Sanit. Hyg. Dev. 5 (3) 456-464. https://doi.org/ 10.2166/washdev.2015.014
SATTERTHWAITE D (2007) The transition to a predominantly urban world and its underpinnings. Human Settlements Discussion Paper Series. International Institute for Environment and Development, London.

SEAL D, BOWN R and PARKER A (2018) Penetrometer tests on 109 pit latrines in Kibera, Nairobi, Kenya. Water SA. 44 (3) 459. https://doi. org/10.4314/wsa.v44i3.13

SKEMPTON AW (1951) The bearing capacity of clays. In: Proceedings of the Building Research Congress, 11-20 September 1951, London.

SOWERS GF and HEDGES CS (1966) Dynamic cone for shallow insitu penetration testing. In: Committee D-18 (ed.) Vane Shear and Cone Penetrations Resistance Testing of In-Situ Soils, ASTM STP 399. ASTM International, Pennsylvania. https://doi.org/10.1520/STP44 $629 \mathrm{~S}$

STRANDE L, MARISKA R and DAMIR B (2014) Faecal Sludge Management: A Systems Approach for Implementation and Operation. IWA Publishing, London. https://doi.org/10.2166/9781780404738

STRAUSS M, LARMIE SA, HEINSS U and MONTANGERO A (2000) Treating faecal sludges in ponds. Water Sci. Technol. 42 (10) 283-290. https://doi.org/10.2166/wst.2000.0662

UNDERDOWN C (2013) Characterisation of synthetic pit latrine sludges and their fluidisation potential. MEng Thesis, University of Cambridge.

UN-DESA (2011) World Urbanization Prospects. United Nations, New York.

VARDANEGA PJ and HAIGH SK (2014) The undrained strengthliquidity index relationship. Can. Geotech. J. 51 (9) 1073-1086. https://doi.org/10.1139/cgj-2013-0169

WOOLLEY SM, BUCKLEY CA, POCOCK J and FOUTCH GL (2014a) Rheological modelling of fresh human faeces. J. Water Sanit. Hyg. Dev. 4 (3) 484-489. https://doi.org/10.2166/washdev.2014.088

WOOLLEY SM, COTTINGHAM RS, POCOCK J and BUCKLEY CA (2014b) Shear rheological properties of fresh human faeces with different moisture content. Water SA. 40 (2) 273-276. https://doi.org/ 10.4314/wsa.v40i2.9

WHO and UNICEF (World Health Organization and United Nations Children's Fund) (2019) Progress on Household Drinking Water, Sanitation and Hygiene 2000-2017. WHO and UNICEF, Geneva. 